\title{
FORCED CONVECTION HEAT TRANSFER, FLOW CONFIGURATION AND THERMAL PERFORMANCE IN A SQUARE CHANNEL WITH MODIFIED V-SHAPED BAFFLES
}

\author{
${ }^{1}$ Amnart Boonloi and ${ }^{2}$ Withada Jedsadaratanachai \\ ${ }^{1}$ Department of Mechanical Engineering Technology, College of Industrial Technology, \\ King Mongkut's University of Technology North Bangkok, Bangkok 10800, Thailand \\ ${ }^{2}$ Department of Mechanical Engineering, Faculty of Engineering, \\ King Mongkut's Institute of Technology Ladkrabang, Bangkok 10520, Thailand
}

Received 2014-03-09; Revised 2014-03-23; Accepted 2014-04-07

ABSTRACT

The influences of modified V-shaped baffle in a square channel for heat transfer and thermal performance enhancement are presented numerically in three Dimensional (3D). The V-shaped baffles are modified in order to comfortable to installation in the square channel. The plates are used for clamping on both the upper and lower V-shaped baffles resulting the modified V-shaped baffle like orifice plate called "V-shaped orifice tubulators, VOT". The effects of Blockage Ratios $(B R=0.05-0.20)$, flow attack angles $\left(\alpha=20^{\circ}, 30^{\circ}\right.$ and $45^{\circ}$ ) and flow directions (V-Downstream and V-Upstream) with a single Pitch Ratio $(\mathrm{PR}=1)$ are investigated for Reynolds number based on the hydraulic diameter of the square channel (Dh), $\operatorname{Re}=100-2000$. The fully developed periodic flow and heat transfer are applied for the computational domain. The SIMPLE algorithm and the finite volume method are used in the current study. The numerical results show that the use of VOT not only increasing heat transfer rate, but also rise up very enlarge pressure loss due to reducing the flow area of the cross sectional area. In addition, the maximum thermal enhancement factors are found around 2.4 and 2.5 for $\mathrm{BR}=0.10, \alpha=30^{\circ}$ at the highest Reynolds number of V-Downstream and V-Upstream, respectively.

Keywords: Finite Volume Method, Laminar Flow, Periodic Concept, Thermal Performance, V-Shaped Baffle

\section{INTRODUCTION}

The V-shaped baffle or rib turbulators have been usually used in order to increase heat transfer and thermal performance in many heat exchanger systems. The uses of $\mathrm{V}$-shaped turbulators can help to augment heat transfer rate by creating jets of the fluid flow, which impinging on the channel wall leading to extremely increase in thermal performance. The V-shaped turbulators not only increase heat transfer rate, but also increase enlarges pressure loss depended on the parameters of the turbulators. Therefore, the parameters; height, spacing, flow attack angle, of Vshaped tablets are important to investigate. Except from the parameters, the installation method and application of Vshaped turbulatos are necessary factors to study for improving the new design of thermal systems.
The new designs of turbulators and their parameters; shape, attach angle, height and space have been studied. Array of V-shaped baffle were used to insert into the channel or tube in heat exchanger to increase in heat transfer rate and efficiencies. The Higher of Blockage Ratio (b/H, BR) of V-baffle give the highest heat transfer rate but also provide very enlarge pressure loss. To reduce the pressure loss of the system, the investigation of pitch spacing or Pitch Ratio (P/H, PR) was reported by (Promvonge et al., 2010; 2012). The results showed that and heat transfer. Peng et al. (2011) studied on both experimentally and numerically for convection heat transfer in channels with different types of ribs; $90^{\circ}$ continuous rib, $90^{\circ}$ interrupted rib, $45^{\circ} \mathrm{V}$-shaped continuous rib, $45^{\circ} \mathrm{V}$ shaped interrupted rib, $60^{\circ} \mathrm{V}$-shaped continuous rib and $60^{\circ}$ $\mathrm{V}$-shaped interrupted rib. The results indicated that the $45^{\circ}$ Corresponding Author: Amnart Boonloi, Department of Mechanical Engineering Technology, College of Industrial Technology, King Mongkut's University of Technology North Bangkok, Bangkok 10800, Thailand 
V-shaped continuous ribs have the highest thermal performance. They also reported the comparison of continuous and interrupted ribs; the V-shaped interrupted ribs give lower heat transfer rate than that from the $\mathrm{V}$ shaped continuous ribs, while the $90^{\circ}$ ribs had the opposite result. Karwa and Chitoshiya (2013) experimentally studied of thermo-hydraulic performance of a solar air heater with $60^{\circ} \mathrm{V}$-down discrete rib roughness on the air flow side of the absorberplate. The enhancement in the thermal efficiency due to the roughness on the absorber plate is found to be $12.5-20 \%$, depending on the airflow rate; higher enhancement is at the lower flow rate were also presented by (Karwa and Chitoshiya, 2013). Singh et al. (2012) studied on thermohydraulic performance caused by flow-attack-angle in V-down rib with a gap in a rectangular duct of solar air heater. They concluded that the thermal enhancement factor was found to be highest at the attach angle of $60^{\circ}$. Except from the results of the previous works, there are found that the use of numerical methods can help to study the mechanism that occurring in the system as Refs. (Subbarayalu and Velappan, 2011; Geetha and Moorthy, 2011).

The single V-shaped baffles placed on one wall were reported by (Boonloi and Jedsadaratanachai, 2013). They concluded that the single $\mathrm{V}$-shaped baffles gave the TEF around 2.44, 2.29 and 2.37 at higher $\mathrm{Re}$ for $\mathrm{BR}=0.3$, 0.3 and 0.4 ; and $P R=1,1.5$ and 2 are, respectively. The discrete $\mathrm{V}$-baffles inserted in the circular tube were presented by (Jedsadaratanachai and Boonloi, 2013). They also concluded the flow structure by using V-baffle and summarized that the TEF were around 2.44, 2.29 and 2.37 with $\mathrm{BR}=0.3,0.3$ and 0.4; and $\mathrm{PR}=1,1.5$ and 2 are, respectively.

The applications of $\mathrm{V}$-shaped turbulators which placed on the walls of the channel have been found that the problems from the installation methods and maintenance. Therefore, the modifications of V-shaped turbulators are investigated to improve the $\mathrm{V}$-shaped turbulators design for comfortable and suitable to apply with industries and types of work with remain the flow structure and heat transfer characteristic similar as V-shaped turbulators.

As above, the new idea that combined between orifice plate and V-shaped turbulators are introduced called "V- shaped orifice turbulators, VOT". The thin plates which clamping the two edges of the V-shaped turbulators help to keep constant configuration of the turbulators and also reduce the gap between walls and the turbulators. The VOT insert in the square channel with inline arrangement due to the clamping plate fixed the configurations of VOT. The effects of the blockage ratios $(\mathrm{BR}=0.05)$, flow attack angle $\left(\alpha=20^{\circ}, 30^{\circ}\right.$ and $\left.45^{\circ}\right)$ and flow direction (V-Downstream and V-pstream) with a single Pitch Ratio $(\mathrm{PR}=1)$ are presented numerically in 3D.

\section{MATERIALS AND METHODS}

\subsection{Flow Description}

The VOT configuration is referred form (Promvonge et al., 2010; 2012; Boonloi and Jedsadaratanachai, 2013; Jedsadaratanachai and Boonloi, 2013). A square channel with VOT inserted is presented in Fig. 1. The air enters the square channel at an inlet temperature, $\mathrm{T}_{\mathrm{in}}$, the channel height, $\mathrm{H}$, is set to $0.05 \mathrm{~m}$ and the channel width equal to $\mathrm{H}, \mathrm{W}=\mathrm{H}$. The Pitch to Height Ratio $(\mathrm{P} / \mathrm{H}, \mathrm{PR})$ is remain constant, $\mathrm{PR}=1$. The VOT Height is defined as the Blockage Ratio (b/H, BR) and, $\alpha$ is known as the flow attack angle. The grid system with 80656 cells is adopted for the computational domain. The cases study in this study are follows as Table $\mathbf{1}$.

The methodologies of this study; boundary conditions, assumptions, verification and mathematical foundations are referred from (Promvonge et al., 2010; 2012; Boonloi and Jedsadaratanachai, 2013; Jedsadaratanachai and Boonloi, 2013).

\subsection{Boundary Conditions, Assumptions and Mathematical Foundations}

The boundary conditions for current model are as follows:

- The periodic boundaries are used in the numerical domain

- The tested fluid is air with a temperature of $300 \mathrm{~K}$ $(\mathrm{Pr}=0.7)$ and enter to the inlet with constant mass flow rate

The inlet and outlet velocity profiles must be identical:

- The physical properties of the air have been assumed to remain constant at average bulk temperature

- Impermeable boundary and no-slip wall conditions have been implemented over the square channels as well as the VOT

- The constant temperature of the square channel wall is maintained at $310 \mathrm{~K}$ while the VOT is assumed at adiabatic wall conditions

The computational domain is following assumptions:

- Steady three-dimensional fluid flow and heat transfer

- The flow is laminar and incompressible

- Constant fluid properties

- Body forces and viscous dissipation are ignored

- Negligible radiation heat transfer 

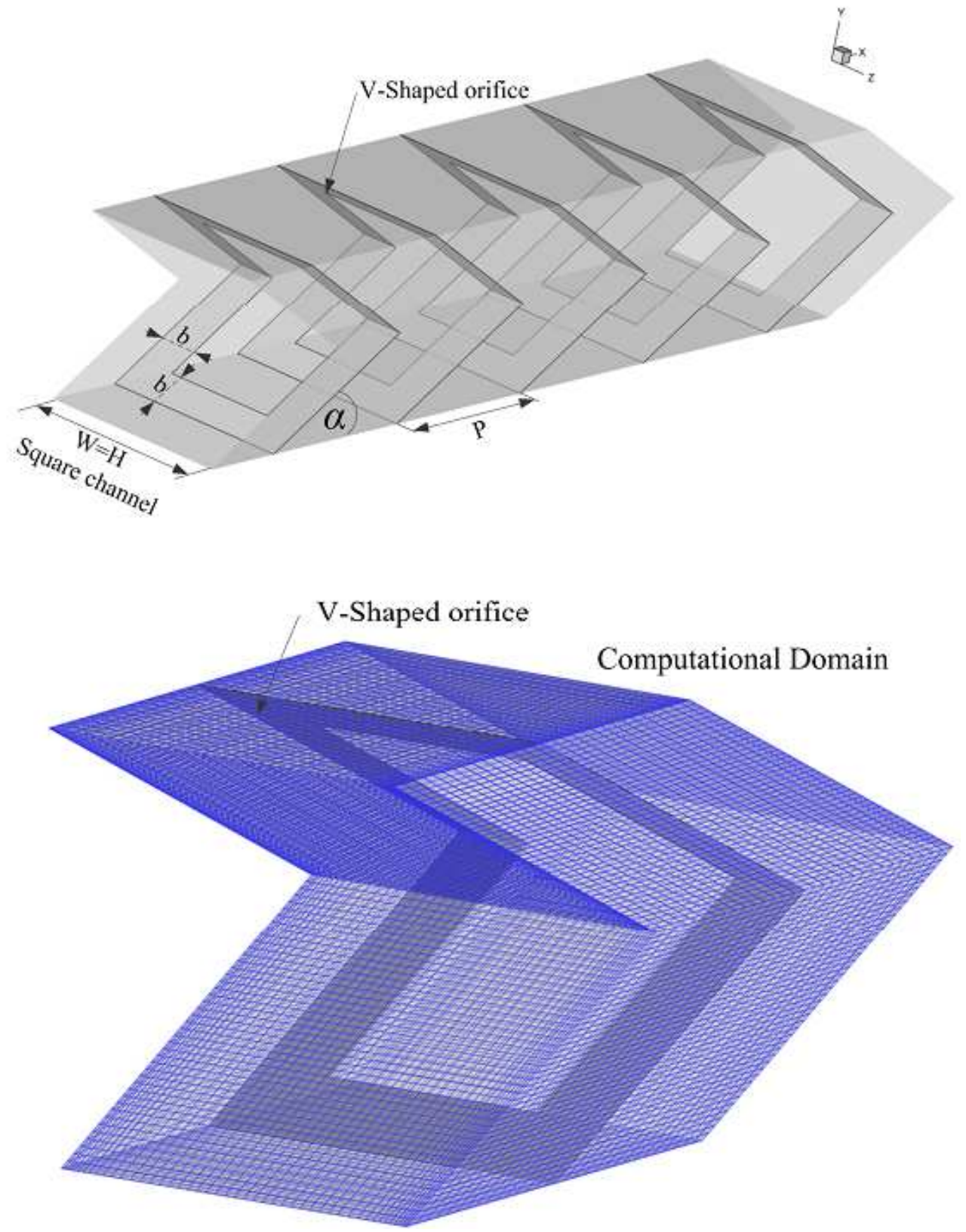

Fig. 1. Square channel geometry and computational domain of periodic flow for VOT

Table 1. Cases study

\begin{tabular}{clll}
$\alpha$ & $\mathrm{BR}$ & $\mathrm{Re}$ & Flow direction \\
\hline $20^{\circ}$ & $0.05-0.20$ & $100-2000$ & V-Downstream \\
$30^{\circ}$ & $0.05-0.20$ & $100-2000$ & V-Downstream \\
& & & V-Upstream \\
$45^{\circ}$ & $0.05-0.20$ & $100-2000$ & V-Downstream \\
\hline
\end{tabular}

Promvonge et al. (2010; 2012; Boonloi and Jedsadaratanachai, 2013; Jedsadaratanachai and Boonloi 2013), based on the above assumptions, the flow in circular tube is governed by the continuity, the NavierStokes and the energy equations.

Apart from the energy equation discretized by the QUICK scheme, the governing equations were 
discretized by the Second Order Upwind (SOU) scheme, decoupling with the SIMPLE algorithm and solved by using a finite volume approach (Patankar, 1980). The solutions were considered to be converged when the normalized residual values were less than $10^{-5}$ for all variables but less than $10^{-9}$ only for the energy equation.

Four parameters of interest in the present work are the Reynolds number, friction factor, Nusselt number and thermal enhancement factor. The Reynolds number is defined as Equation 1:

$$
\mathrm{Re}=\rho \overline{\mathrm{uD}} / \mu
$$

The friction factor, $\mathrm{f}$ is computed by pressure drop, $\Delta \mathrm{p}$ across the length of the periodic channel, $\mathrm{L}=\mathrm{P}$ as Equation 2:

$$
\mathrm{f}=\frac{(\Delta \mathrm{p} / \mathrm{L}) \mathrm{D}}{\frac{1}{2} \rho \overline{\mathrm{u}}^{2}}
$$

The heat transfer is measured by the local Nusselt numberwhich can be written as Equation 3:

$$
\mathrm{Nu}_{\mathrm{x}}=\frac{\mathrm{h}_{\mathrm{x}} \mathrm{D}}{\mathrm{k}}
$$

The average Nusselt number can be obtained by Equation 4:

$$
\mathrm{Nu}=\frac{1}{\mathrm{~A}} \int \mathrm{Nu}_{\mathrm{x}} \partial \mathrm{A}
$$

The Thermal Enhancement Factor (TEF) is defined as the ratio of the heat transfer coefficient of an augmented surface, $h$ to that of a smooth surface, h0, at an equal pumping power and given by Equation 5:

$$
\mathrm{TEF}=\left.\frac{\mathrm{h}}{\mathrm{h}_{0}}\right|_{\mathrm{pp}}=\left.\frac{\mathrm{Nu}}{\mathrm{Nu}_{0}}\right|_{\mathrm{pp}}=\left(\mathrm{Nu} / \mathrm{Nu}_{0}\right) /\left(\mathrm{f} / \mathrm{f}_{0}\right)^{1 / 3}
$$

where, $\mathrm{Nu}_{0}$ and $\mathrm{f}_{0}$ stand for Nusselt number and friction factor for the smooth channel, respectively.

\subsection{Verification of the Smooth Square Channel}

The validations on both Nusselt number and friction factor are compared between the present prediction and the exact solution under similar operating conditions. The result is found to be in excellent agreement with exact solution values obtained from the open literature (Incropera and Dewitt, 2006) for both the $\mathrm{Nu}$ and $\mathrm{f}$, less than $\pm 0.42 \%$ deviation.

\section{RESULTS AND DISCUSSION}

\subsection{Flow Configurations}

As the main idea, the remaining of the flow structure as $\mathrm{V}$-shaped turbulators is very important to investigate. The flow configurations of the VOT are presented in terms of streamlines in transverse planes and streamlines impinging jets on the channel walls as Fig. 2-5.

Figure 2a and $\mathbf{b}$ shows the streamlines in transverse planes for $\mathrm{VOT}$ at $\mathrm{Re}=500, \mathrm{BR}=0.20$ and $\alpha=30^{\circ}$ for (a) V-Downstream and (b) V-Upstream, respectively, while the Fig. 3 present the details for each plane in similar cases. As seen, the flow structures in both cases provide similar as V-shaped baffle (Boonloi and Jedsadaratanachai, 2013). The four main vortex flows appear, though the testing channel as plane A1-A5 and B1-B5, respectively, for V-Downstream and VUpstream, but different in rotating direction. The cores of the vortex flows are changed depending on the position of the VOT. The 5th plane, the configurations of the vortex flows on both case $\mathrm{s}$ are seen similar as 1st plane due to the fully developed periodic concept that use for the computational domain.

In addition, the V-downstream and V-Upstream give the counter-rotating flows with common-flow-down and common-flow-up, respectively, as shown in Fig. 4a and $\mathbf{b}$, when considering at the lower part of the plane.

To ensure, the checking of the longitudinal vortex flows or streamlines impinging jets on the square channel walls is presented in Fig. 5a and b, respectively, for lower wall and sidewall of the square channel at V-Downstream case, $\mathrm{Re}=500, \mathrm{BR}=0.20$ and $\alpha=30^{\circ}$. There are found that the VOT can create the impinging jet flows similar as $\mathrm{V}$-shaped turbulators and the impinging regimes give the higher heat transfer rate in comparison with other area. This means that the use of the VOT can induce the flow configurations related as $\mathrm{V}$-shaped turbulators.

\subsection{Heat Etransfer Ceharacteristic}

Due to the relationship between flow configurations and heat transfer characteristics, the impinging jets of the fluid flow lead to the increasing heat transfer rate as Fig. 5. The heat transfer behaviors with different flow direction, V-Downstream and VUpstream are depicted in Fig. 6a and b, respectively, in the form of Nux contours of the square channel walls at $\operatorname{Re}=500, \mathrm{BR}=0.20$ and $\alpha=30^{\circ}$. 


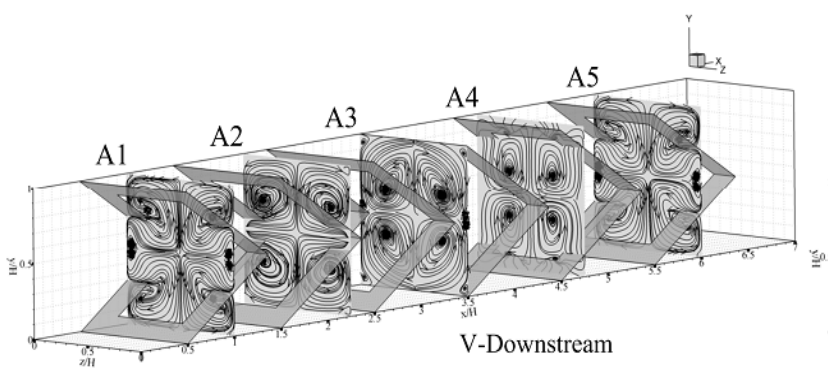

(a)

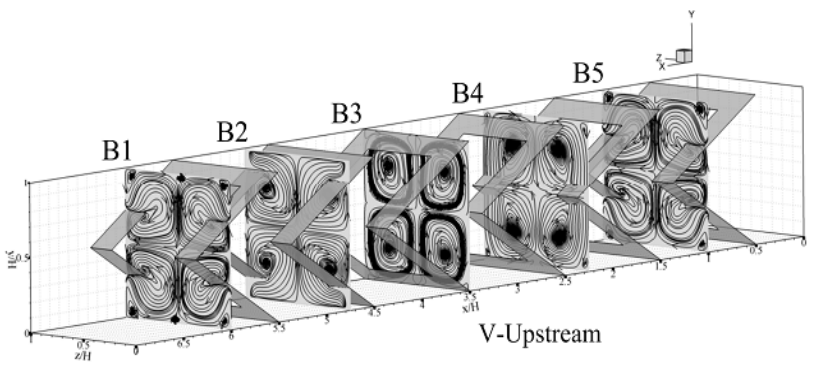

(b)

Fig. 2. Streamlines in transverse planes for VOT (a) V-Downstream and (b) V-Upstream at Re $=500, B R=0.20$ and $\alpha=30^{\circ}$
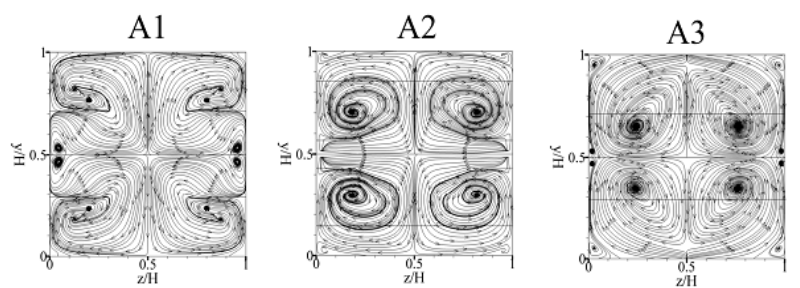

A5
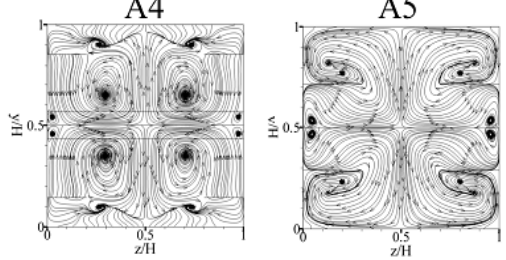

(a)
B1

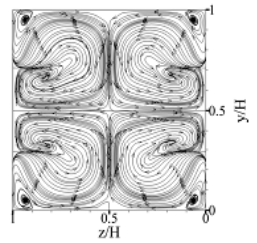

B2

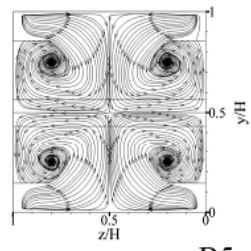

B5
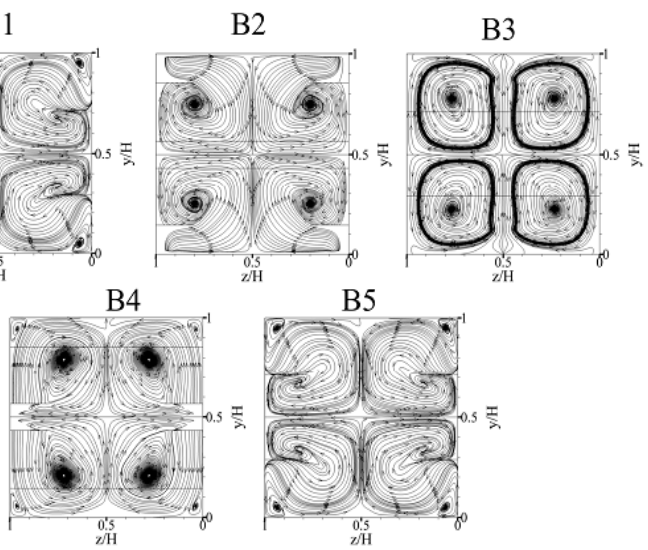

(b)

Fig. 3. Details of streamlines in transverse planes for VOT (a) V-Downstream and (b) V-Upstream at $\operatorname{Re}=500, B R=0.20$ and $\alpha=30^{\circ}$

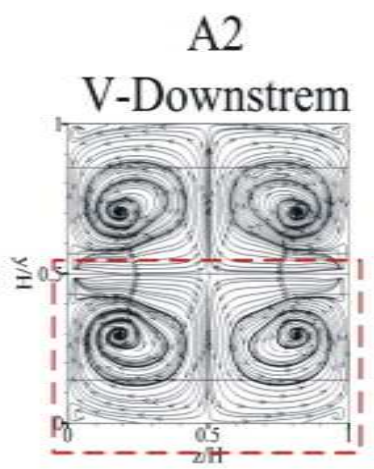

\section{Common-flow-down}

(a)
B2

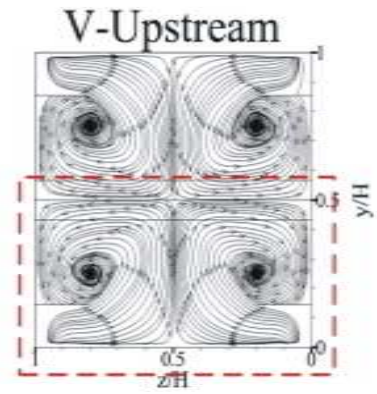

(b)

Fig. 4. Flow descriptions in transverse planes for VOT (a) V-Downstream and (b) V-Upstream at $\operatorname{Re}=500, \mathrm{BR}=0.20$ and $\alpha=30^{\circ}$ 
Amnart Boonloi and Withada Jedsadaratanachai / Journal of Mathematics and Statistics 10 (2): 201-210, 2014

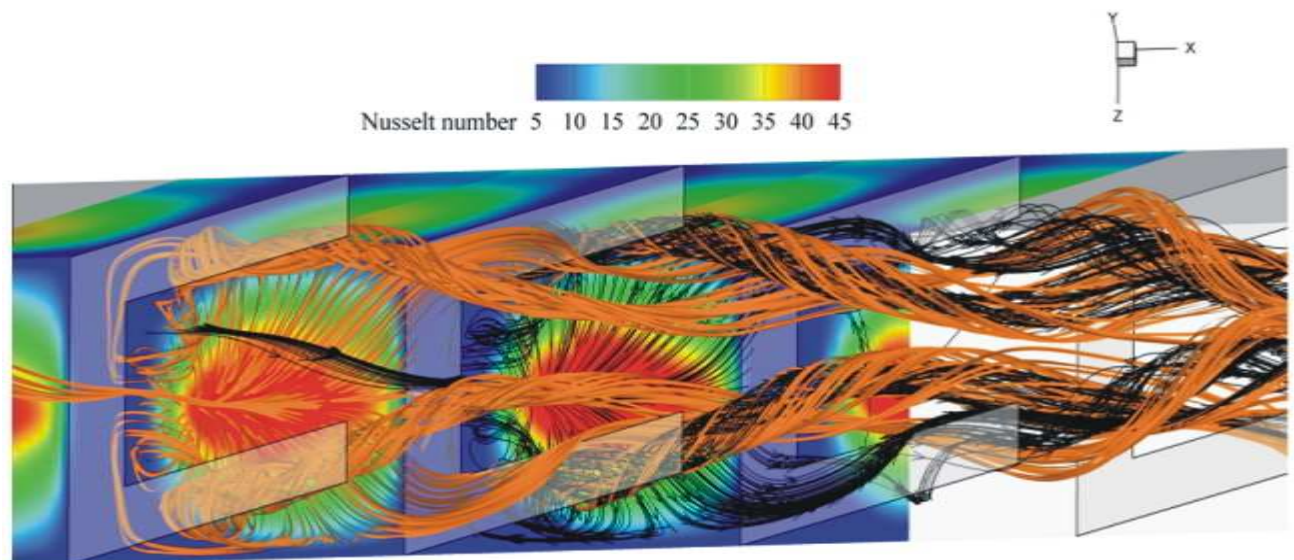

(a)

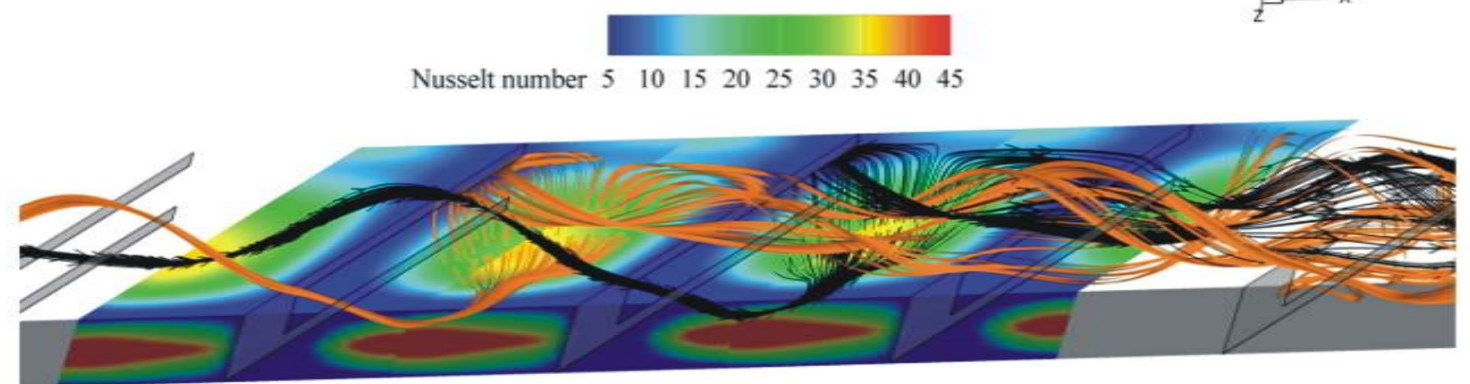

(b)

Fig. 5. Flow descriptions in impingment jet on the walls for VOT (a) lower wall and (b) sidewall at $\operatorname{Re}=500, \mathrm{BR}=0.20, \alpha=30^{\circ}$ and V-pointing downstream

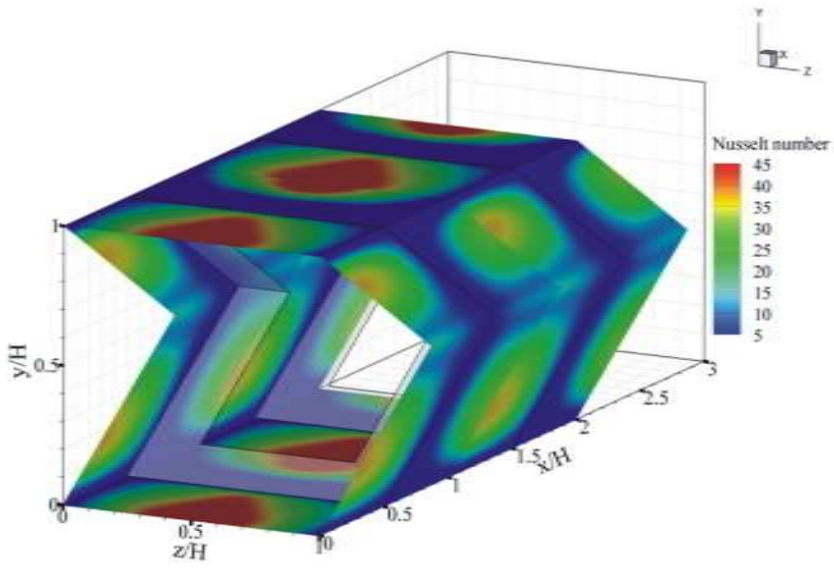

(a)

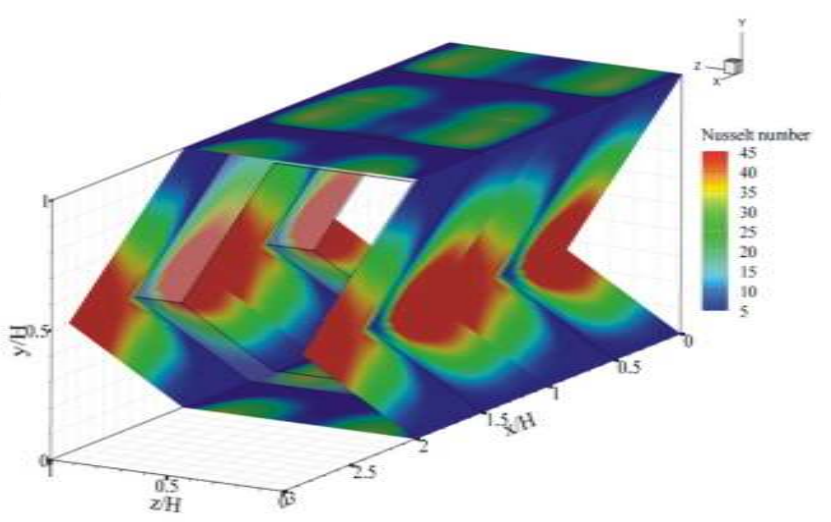

(b)

Fig. 6. Nux contours for VOT (a) V-Downstream and (b) V-Upstream at $\operatorname{Re}=500, B R=0.20$ and $\alpha=30^{\circ}$ 


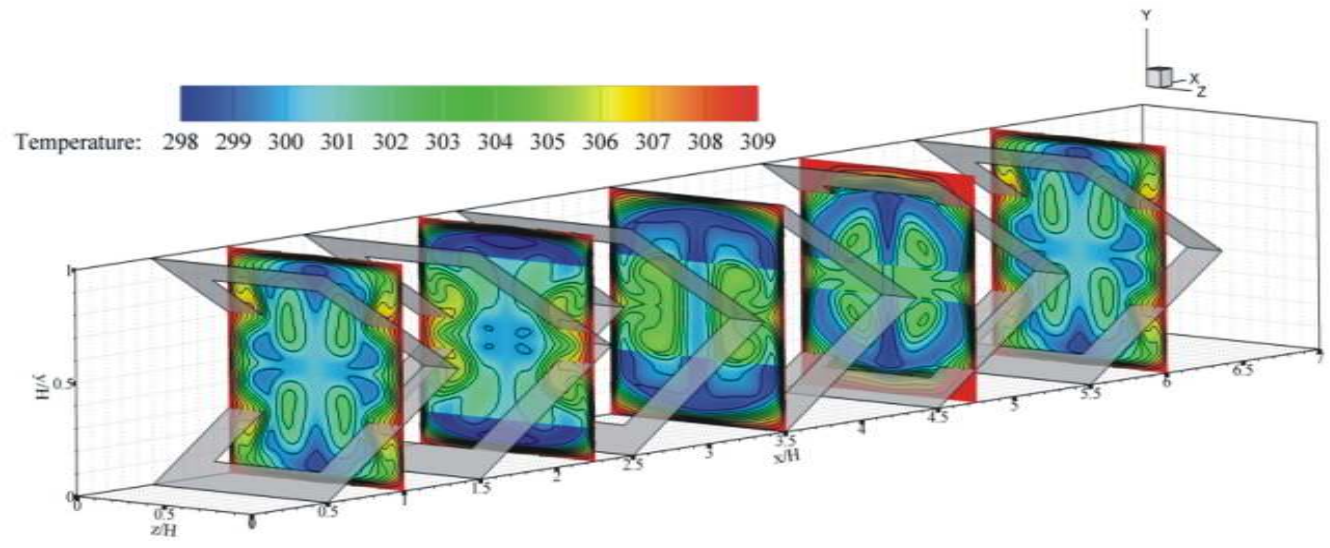

(a)

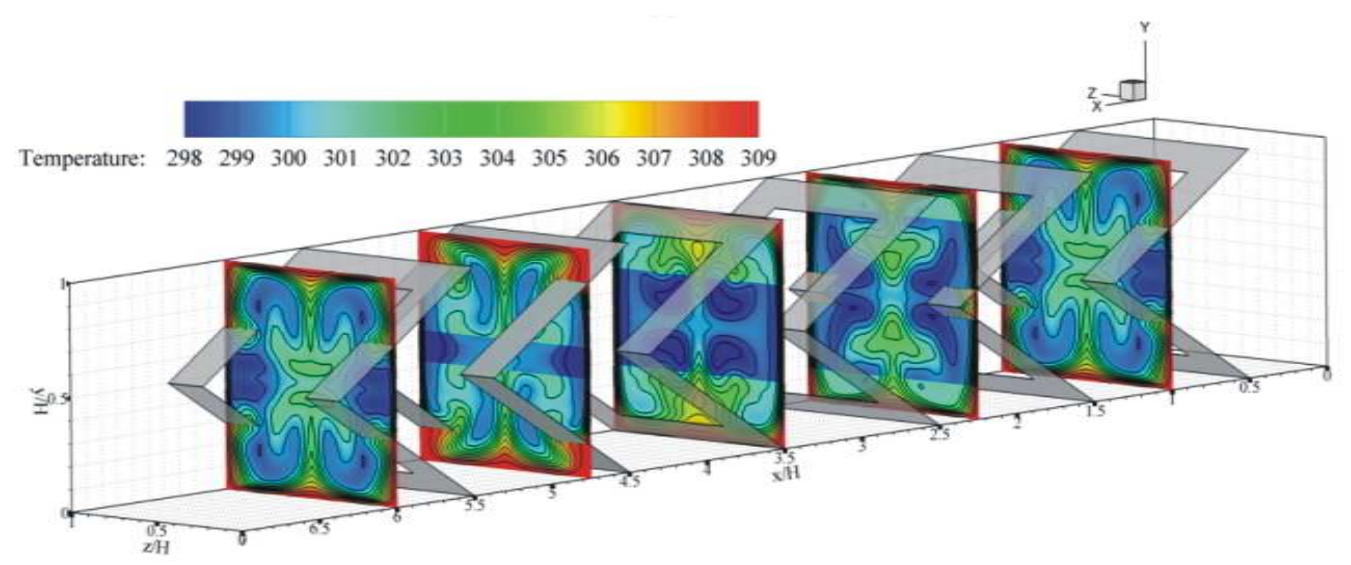

(b)

Fig. 7. Contours temperature in transverse planes for VOT (a) V-Downstream and (b) V-Upstream at $\mathrm{Re}=500, \mathrm{BR}=0.20$ and $\alpha=30^{\circ}$

There are seen that the differences in rotating direction, resulting the dissimilarity of the heat transfer behaviors. The V-Downstream case, the higher heat transfer regimes are found at the upper and lower walls of the square channel while the VUpstream case provides the higher heat transfer rate at the sidewall regions. The heat transfer behavior of all ranges studied are seem to be likely.

The uses of the VOT can produce good mixing of the temperature between the middle of the channel and near the walls as Fig. 7. The similar results are found on both V-Downstream and V-upstream cases, respectively, as Fig. 7a and b.

Except from the above results, there are notices that the regimes behind of the VOT, the mixing of the fluid flow performs not good in both cases causing the vortex flows cannot impinge this region lead to the lowest heat transfer rate behind the VOT regimes.

\subsection{Performance Eevaluation}

The performance evaluations of the VOT are presented in terms of the variations of $\mathrm{Nu} / \mathrm{Nu}_{0}, \mathrm{f} / \mathrm{f}_{0}$ and TEF as Fig. 8-10, respectively. In general, the uses $f$ VOT provide the higher heat transfer rate and also increase the pressure loss than the smooth channel with no VOT. The increasing BR and Re lead to the rise of $\mathrm{Nu} / \mathrm{Nu}_{0}$ and $\mathrm{f} / \mathrm{f}_{0}$ values for all cases.

The $\mathrm{Nu} / \mathrm{Nu}_{0}$ values, the $20^{\circ}$ gives the highest heat transfer rate at the highest Reynolds number and BR around 7.5 times over the smooth channel. In range studied, the $\mathrm{Nu} / \mathrm{Nu} 0$ values are found to be about 1-7.5 times depended on BR, $\operatorname{Re}$ and $\alpha$. Effect of flow directional on heat transfer are also presented in Fig. 8b. The V-Upstream cases, perform higher heat transfer rate than the V-Downstream cases. The heat transfer rates for V-Upstream are around 1-13.5 times higher than the smooth channel. This means that the V-Upstream gives 
two times higher heat transfer rate than the V- Downstream. The reasons of this may be that the optimum longitudinal range of vortex flows which creating from $20^{\circ} \mathrm{V}$-Upstream is the best range for impinging jets of the fluid flow.

The increasing Re, BR and $\alpha$ lead to the rising $\mathrm{f} / \mathrm{f}_{0}$ values as Fig. 9. The V-Upstream cases show the

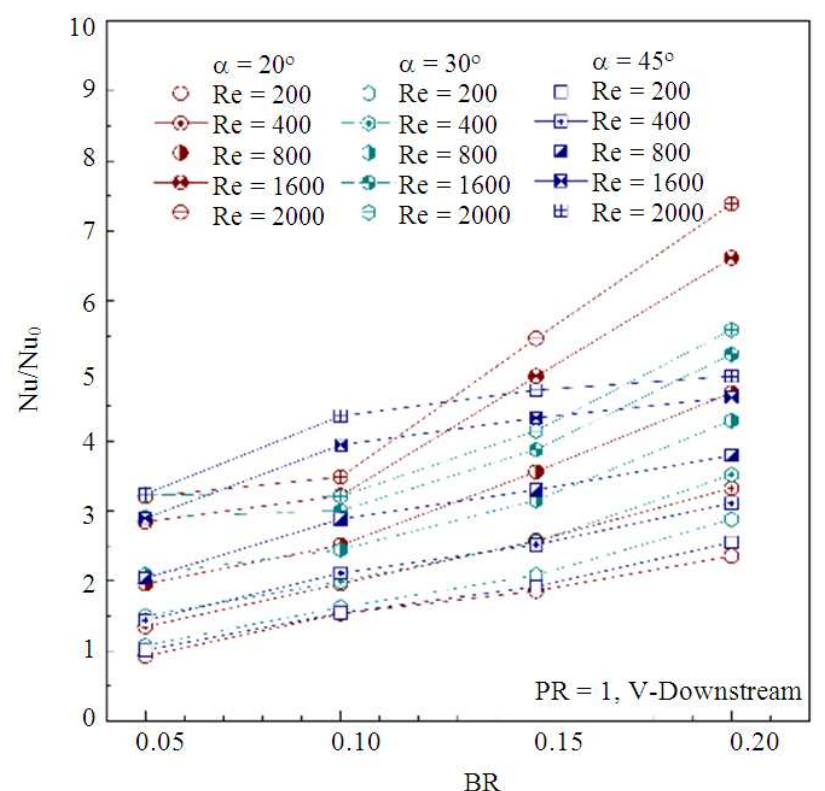

(a) higher friction factor than V-Downstream, especially, $\alpha=45^{\circ}$ that gives the highest friction factor around 400 times higher than the smooth channel. In range studied, the $\mathrm{f} / \mathrm{f}_{0}$ value are found around 1-230 and 1400 times over the smooth channel for V-Downstream and V-Upstream, respectively.

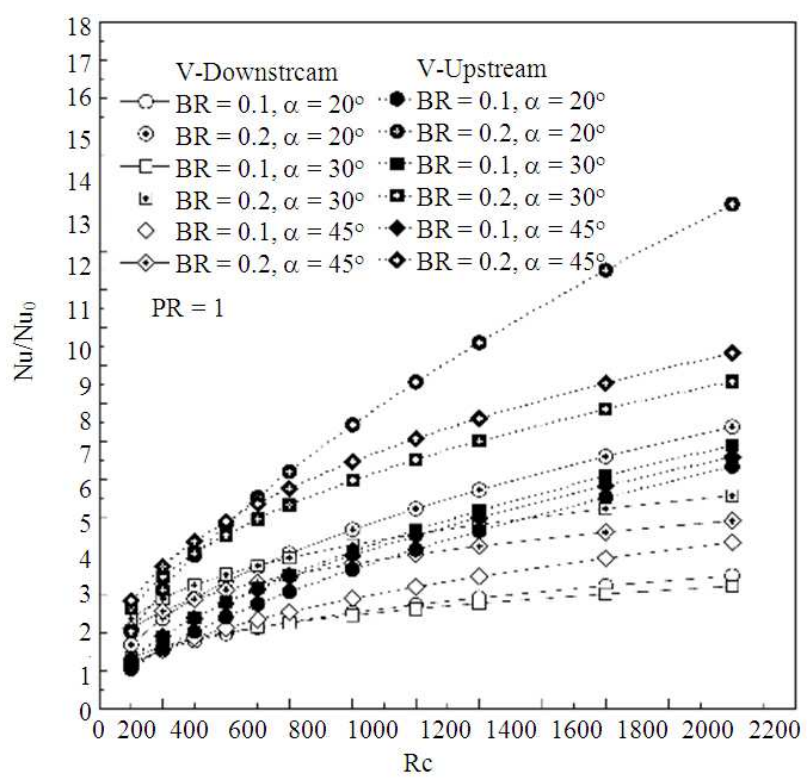

(b)

Fig. 8. (a) The variations of the $\mathrm{Nu} / \mathrm{Nu}_{0}$ with $\mathrm{BR}$ for $\mathrm{V}$-downstream and (b) the variations of the $\mathrm{Nu} / \mathrm{Nu}_{0}$ with $\mathrm{Re}$ at various flow directions

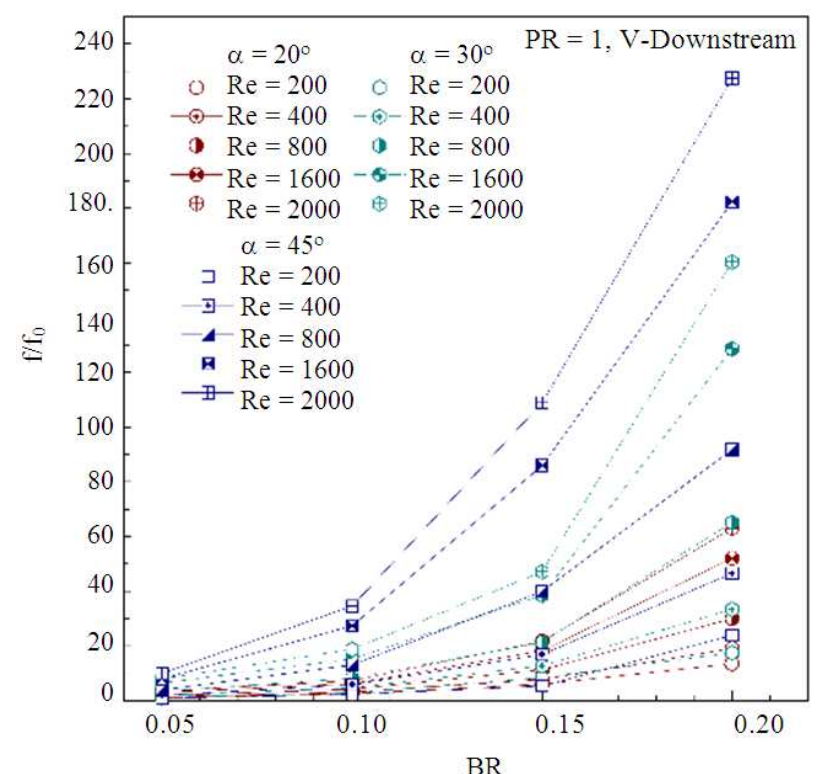

(a)

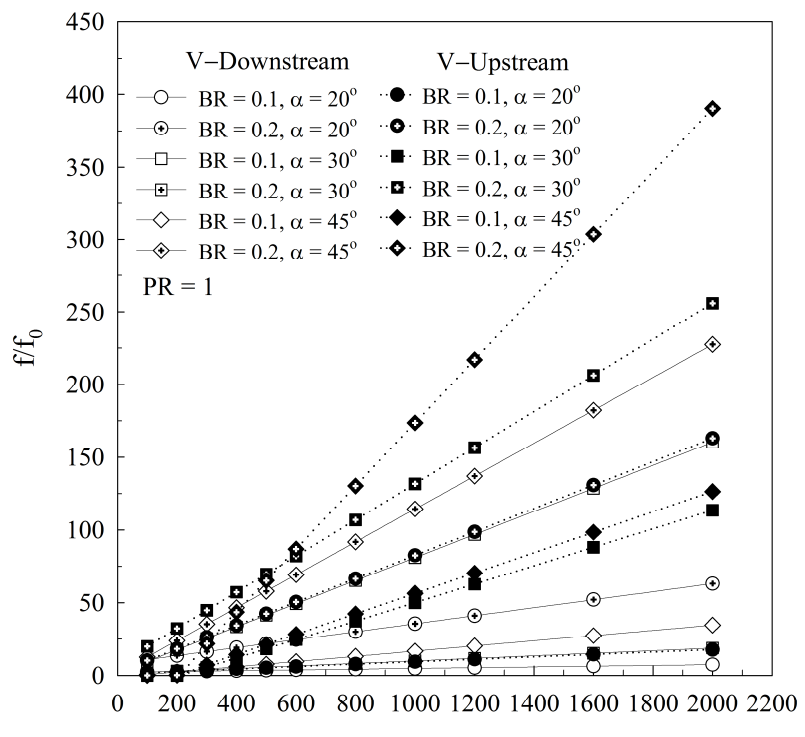

$\mathrm{Re}$
(b)

Fig. 9. (a) The variations of the $f / f_{0}$ with $B R$ for $V$-downstream and (b) the variations of the $f / f_{0}$ with $R e$ at various flow directions 


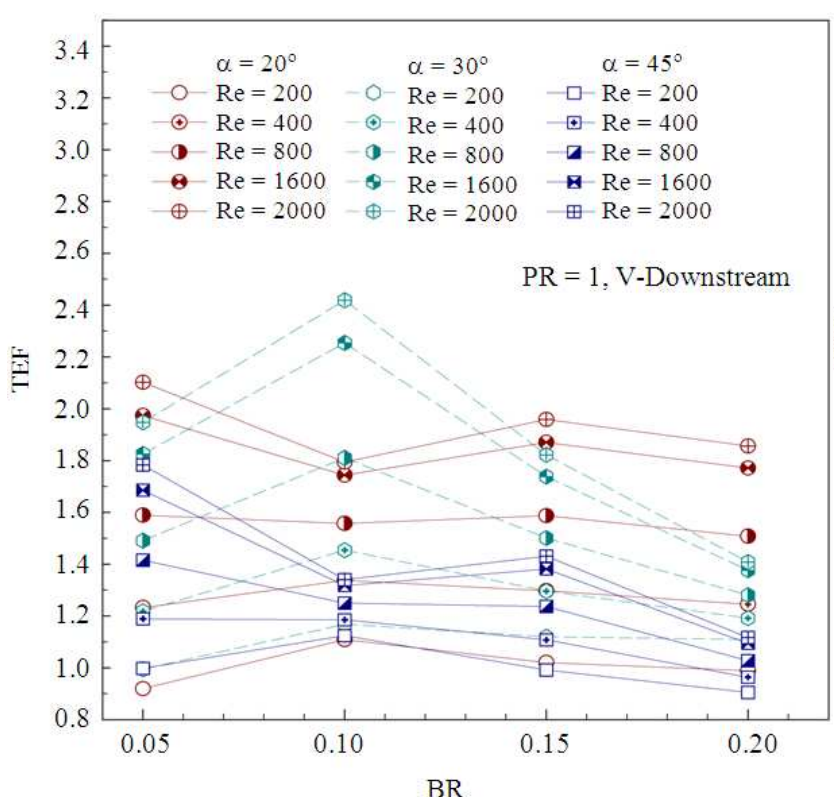

(a)

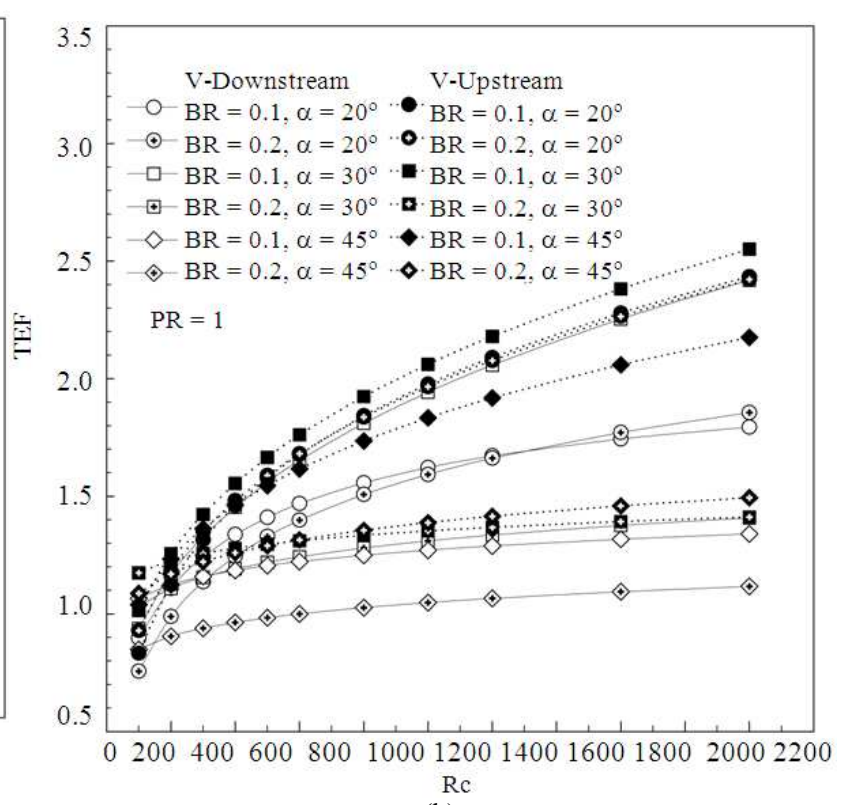

(b)

Fig. 10. (a) The variations of the TEF with $B R$ for $V$-downstream and (b) the variations of the TEF with Re at various flow directions

The TEF values are vary between 0.7-2.5 dependedon BR, $\mathrm{Re}, \alpha$ and flow direction. The optimum TEF is found at BR $=0.10, \alpha=30^{\circ}$ and $\mathrm{Re}=2000$ around 2.4 and 2.5 for $\mathrm{V}$ Downstream and V-Upstream, respectively.

\section{CONCLUSION}

The 3D numerical investigations on fully developed periodic laminar forced convection in square channel with a modified V-baffle or V-shaped orifice turbulators, VOT are presented. The effects of BR, Re, $\alpha$ and flow direction are studied. The numerical results show that the use of VOT gives a higher heat transfer rate and the friction factor than the smooth channel. The flow structures and heat transfer behaviors of the VOT are found similar as-shaped turbulators. The heat transfer increasing around 1-7.5 and 1-13.5 times over the smooth channel for V-Downstream and V-Upstream, respectively, while the pressure loss have very enlarged around 1-400 times due to the VOT configuration and the clamping plate. The maximum TEF is found at $\mathrm{BR}=$ $0.10, \alpha=30^{\circ}$ and $\mathrm{Re}=2000$ around 2.4 and 2.5 for $\mathrm{V}$ Downstream and V-Upstream, respectively.

\section{ACKNOWLEDGEMENT}

This researcher was funded by College of Industrial Technology, King Mongkut's University of Technology North Bangkok, Thailand.
The researchers would like to thank Assoc. Prof. Dr. Pongjet Promvonge for suggestions.

\section{REFERENCES}

Boonloi, A. and W. Jedsadaratanachai, 2013. 3D numerical study on laminar forced convection in V-baffled square channel. Am. J. Applied Sci., 10: 1287-1297. DOI: 10.3844/ajassp.2013.1287.1297

Geetha, P. and M.B.K. Moorthy, 2011. Viscous dissipation effect on steady free convection and mass transfer flow past a semi-infinite flat plate. J. Comput. Sci., 7: 1113-1118. DOI: 10.3844/jcssp.2011.1113.1118

Incropera, F. and P.D. Dewitt, 2006. Introduction to Heat Transfer. 5th Edn., John Wiley and Sons Inc., Hoboken, ISBN-10: 0471457272, pp: 912.

Jedsadaratanachai, W. and A. Boonloi, 2013. Energy performance improvement, flow behavior and heat transfer investigation in a circular tube with V-downstream discrete baffles. J. Math. Stat., 9: 339-348. DOI: 10.3844/jmssp.2013.339.348

Karwa, R. and G. Chitoshiya, 2013. Performance study of solar air heater having V-down discrete ribs on absorber plate. Renew. Energy, 55: 939955. DOI: 10.1016/j.energy.2013.03.068 
Patankar, S.V., 1980. Numerical Heat Transfer and Fluid Flow. 1st Edn., McGraw-Hill, New York, ISBN-10: 0891165223, pp: 197.

Peng, W., P.X. Jiang, Y.P. Wang and B.Y. Wei, 2011. Experimental and numerical investigation of convection heat transfer in channels with different types of ribs. Applied Therm. Eng., 31: 2702-2708. DOI: 10.1016/j.applthermaleng.2011.04.040

Promvonge, P., W. Jedsadaratanachai and S. Kwankaomeng, 2010. Numerical study of laminarflow and heat transfer in square channel with $30^{\circ}$ inline angled baffle turbulators. Applied Therm. Eng., $\quad 30$ : 1292-1303. 10.1016/j.applthermaleng.2010.02.014
Promvonge, P., W. Jedsadaratanachai, S. Kwankaomeng and C. Thianpong, 2012. 3D simulation of laminar flow and heat transfer in V-baffled square channel. Int. Commun. Heat Mass Transfer, 39: 85-93. DOI: 10.1016/j.icheatmasstransfer.2011.09.004

Singh, S., S. Chander and J.S. Saini, 2012. Investigations on thermo-hydraulic performance due to flowattackangle in $\mathrm{V}$-down rib with gap in a rectangular duct of solar air heater. Applied Energy, 97: 907912. DOI: 10.1016/j.apenergy.2011.11.090

Subbarayalu, G. and S. Velappan, 2011. Magneto convection in tilted square cavity with differentially thermally active vertical walls. J. Math. Stat., 7: 149-156. DOI: 10.3844/jmssp.2011.149.156 